Journal of World Architecture

Review Article

\title{
Application of Aesthetic Art and Culture in Interior Design
}

\author{
Yuting Wang \\ Xiaowangzi Design Limited, Nantong 226001, Jiangsu Province, China
}

\begin{abstract}
With the improvement of people's living standard, the living environment needs to be more livable and comfortable. This paper analyzes the importance of aesthetic art and culture in interior design and discusses the application of aesthetic art and culture in interior design.
\end{abstract}

Keywords: Aesthetic art culture; Interior design; Application

Publication date: September, 2020

Publication online: 30 September, 2020

*Corresponding author: Yuting Wang, Xiaowangzisheji@163.com

\section{Introduction}

Interior design is an architectural aesthetic that has been incorporated into the living environment as a form of art and design. As people's standard of living continues to improve, so does their aesthetic level, which is not limited to simple home decoration, but rather the pursuit of higher aesthetics. A more comfortable living environment is created through the organic integration of people and the living environment. In the actual interior design process, there are many factors that can affect the final design. Therefore, designers must consider a variety of factors in order to create comfortable spaces that meet people's practical needs and provide them with a certain aesthetic value in real life.

\section{The connotation of aesthetic art and culture}

With the development and growth of society, aesthetic art and culture has attracted attention and has begun to be widely used in interior design. Revealed through the concrete. The use of aesthetic art culture as a philosophical and theoretical guiding principle for modern interior design allows the design of appropriate living environments. Aesthetic art derives from classical and traditional aesthetics, inheriting both classical and traditional beauty and expressing contemporary beauty in modern society ${ }^{[1-2]}$.

\section{Elements of aesthetic art in interior design}

Aesthetics play an important role in interior design. Under the guidance of aesthetic art, a relaxed and comfortable living environment is created, which enriches people's spiritual life. In interior design, aesthetic elements are reflected in the following aspects:

\subsection{Spatial elements in the aesthetic arts}

The basic starting point of interior design is to bring a good visual experience to people by rationalizing the design of space. To do this, interior designers need to make major breakthroughs, innovate and reform traditional space settings, and design living environments that meet people's aesthetic needs for space.

\subsection{The Element of Color in Aesthetic Art}

Color can affect people's psychology or mood. The scientific and rational understanding and correct use of color elements can create a comfortable and reasonable living environment. Therefore, during the interior design process, the designer must completely adhere to the color rules of the design in order to create the perfect living environment.

\subsection{Decorative elements in the aesthetic arts}

The most important factor in creating the perfect living environment is the proper decoration of the walls, pillars and ceilings of the room. By analyzing the actual situation and using different decorative materials rationally and in different places, the designed 
interior environment is not only aesthetically pleasing, but also the visual impact can be changed. Aesthetic requirements are met to the maximum extent ${ }^{[3-5]}$.

\section{The importance of aesthetic artistic elements in interior design}

The aesthetic arts are important guides and provide a very pleasant environment for people to live in. Among them, people get a very rich spiritual life and their life becomes very rich. Therefore, aesthetic elements play an important role in the interior design development process. First of all, there are some basic points that exist in operating aesthetics and art when it comes to interior design in the spatial element dimension. For the perfect design of the space, people feel beautiful. As a result, interior designers must be brave enough to push the envelope, innovate across the board, and make key innovations in past spatial environments. The resulting living environment must be closely integrated with people's spatial and aesthetic needs. Secondly, aesthetically, the element of color will have a significant impact on people's psychology or emotions. Therefore, colors must be accurately understood from a scientific point of view. In this way, a reasonable living environment can be created for people. Therefore, when faced with interior design work, designers must start with the color principles of design to provide a quality living environment. Decorative elements covered with aesthetic art will complete the living environment. Important aspects involved are the improvement of walls, columns and ceilings that decorate the interior of the room. For the analysis of rationalization based on specific conditions, faced with different decorative materials and the use of different decorative materials in different places. The interior environment displayed in this way can meet the needs of people ${ }^{[4]}$.

\subsection{Images are the language of the designer}

Pencil and paper are the most straightforward and quickest way to design. Most of the process of imagining and thinking is done with simple paper and pencil. Interior design requires a foundation in fine arts, according to the nature of use of the building, the environment and the corresponding standards, using material technology and architectural design principles to create an indoor environment that is functionally rational, comfortable and beautiful, and meets the material and spiritual needs of people. The learning process is combined with the application of computer graphics modeling techniques to enhance the study of art techniques, and efforts are made to learn and study in depth to add some aesthetic elements to mechanical drawing to create more possibilities for aesthetic practice.

\section{The application of aesthetic art culture in interior design}

\subsection{Focus on Aesthetic Art Theory Guidance}

Aesthetic art involves many elements. For example, with the help of aesthetic art theories, the perfect blend of classical, fashionable and traditional beauty makes the practice more comprehensive and relevant. In interior design work, the designer will not only focus on the previous neat and compliant design elements, but will also make proper settings and plans for the furniture, while following modern aesthetic guidelines. In this way, the value of modern beauty will be fully reflected, and the theory in interior environmental art and design should be used as a guide to effectively meet the aesthetic needs of modern people.

\subsection{Formation of a celestial state of mind}

One of the important ancient ideas is that the idea of harmony between man and nature is of great value and importance in architectural aesthetics. From the point of view of ancient Chinese design, regular forms could not fundamentally meet the requirements of modern design, starting from the field of modern interior design, these forms were achieved through simplification. Therefore, in the development of interior design works, the requirements of the works should be based on the actual development of modern society, with an eye on the aesthetic needs of people and with full attention to the modern aesthetic needs ${ }^{[3]}$. At the same time, the focus is not to abandon all traditional Chinese aesthetic concepts, but to develop and inherit them.

\subsection{Organic combination of color and free simplicity}

It must be strictly adhered to from the point of view of the color principle, which will to some extent emphasize and reflect the aesthetics of interior design, whether confronted with light or dark shades. In interior design work, color elements should be very widely used and of high quality, people no longer use conventional formats and are no longer limited to monotonous color designs. Based on the principle of color, a modern aesthetic can be perfectly realized. In the process, simplicity and randomness are combined to meet the needs of modern interior design. From a simple point of view, people are free to improve their interiors as they wish in order to 
form a perfect, high-quality interior environment. In this way, people's aesthetic perceptions and needs will also be met ${ }^{[6]}$. In terms of traditional and complex interior design, it reduces the appropriate complexity and makes for a more comfortable living environment compared to modern, simple and casual designs.

\subsection{Demonstrates humanism}

Guided by contemporary aesthetics, we should focus on contemporary interior design that closely integrates theory and practical content and gives life and strength to decorative design within the context of the core innovations of the concept. In order to develop modern human society, we need to develop in harmony with nature in order to form a model of unity and harmony. Therefore, when interior design is carried out, the designer must meet the view of the walls, roof, windows, etc. so that the natural outdoor environment comes into view of the people inside the house.

\subsection{Aesthetic combination of scientific and artistic qualities}

When it comes to interior design, aesthetic art plays a role in its character and value. Bringing science and art together. Scientific design should focus not only on the arrangement and use of space, but also on materials and structures to ensure the aesthetic appeal of certain techniques. This ensures the comfort and efficiency of the interior environment. When these two aspects are closely combined, the beauty of modern interior design work is perfectly reflected. In the ongoing development of the social sciences, it shows a relatively fast pace and there are opportunities for scientific integration in the sphere of life and production ${ }^{[1]}$.

\section{The application prospect of aesthetic art culture in interior design}

With the development and growth of society, people's thoughts are also advancing with the times. However, people's pursuit of beauty is endless, and aesthetic concepts are also constantly developing and improving. Modern interior design is guided by aesthetics and has entered a wide path of development. As people continue to explore and pursue, interior design will incorporate more elements of aesthetic art and culture, interior design will find more beautiful things to use in a more humane interior design. The living environment created for mankind will also be more harmonious, comfortable and perfect.

\section{Conclusion}

In conclusion, aesthetic art culture should be used as an important theoretical guide in the process of carrying out interior design work. Where beauty and science are closely integrated, the human environment can achieve a unified effect and thus make better use of the value of beauty. When human activities are closely integrated with the natural environment, people will be more comfortable physically and mentally and will have a greater awareness of beauty. From the overall layout, with aesthetic art guidance as the background, the interior environmental design work is more rationalized based on the development with the times, perfect design to meet the needs of people's lives.

\section{References}

[1] Wang L, Chen X. On the presentation and application of mural art in interior design[J]. Journal of Chongqing Institute of Science and Technology (Social Science Edition), 2020(4): 9194.

[2] Chen FY, Chen HH, Cheng JH. Research on the Application of East Pakistani Cultural Elements in Interior Art Design[J]. Art Tech, 2019, 32(7): 226-281.

[3] Yang XQ. Application of tea culture soft decoration materials in the design of interior environmental art[J]. Fujian Tea, 2017, 39(8): 261-262.

[4] Luan S. The application of the cultural heritage of Northeast folk in interior design - a study on Manchu paper-cutting art[J]. Art Tech, 2015, 28(9): 226.

[5] Zhan QC,Wang QQ. Application of Chinese traditional culture and art in interior design[J]. Art Technology, 2013, 26(2): 186.

[6] Yang L. The Application Value of Chinese Classical Loulan Art and Culture in Interior Design[J]. China Market, 2010(18): 130133. 